\title{
Reducing Torque Ripples of the Axial Flux PM Motors by Magnet Stepping and Shifting
}

\author{
Emrah Cetin \\ Electrical and Electronics Engineering Dpt \\ Erciyes University \\ Kayseri, Turkey \\ emrahcetin@erciyes.edu.tr
}

\author{
Ferhat Daldaban \\ Electrical and Electronics Engineering Dpt \\ Erciyes University \\ Kayseri, Turkey \\ daldaban@erciyes.edu.tr
}

\begin{abstract}
Higher efficiency on electric machines is the research goal of many studies. An example is the axial flux permanent magnet machines. These machines have some advantages like their watt/kg efficiency and torque density. This study aims to develop the performance characteristics of the axial flux permanent magnet machines. A new rotor magnet poles design in axial flux machines is suggested to mitigate the torque ripples. The method of stepping and shifting of the magnets is used. Two different designs are compared to verify the proposed approach. 3D finite element analysis is used for simulations. Torque ripple and back electromotive force waveforms are obtained from computer analysis. As a conclusion, the suggested method is found to be useable and mitigates the torque ripples. In addition to that, back EMF waveforms are turned to sinusoidal by the suggested design.
\end{abstract}

Keywords-axial flux machines; step and shift; rotor magnet poles; torque ripple; back emf; permanent-magnet machines

\section{INTRODUCTION}

Electric machine design became crucial since the necessities of higher efficiency constantly increase for many different applications. If the application is torque sensitive and of low acoustic noise, torque ripples must be eliminated. Torque ripples must be taken into account in every machine design. Torque ripple occurs in case of interactions between stator slots and rotor magnet poles. Axial flux permanent magnet (AFPM) machines have high power density, small volume and are convenient for many applications [1], but have particular problems in manufacturing [2]. Moreover, AFPM machines have torque ripples as many other permanent magnet machine types. Most of the applications are torque sensitive, so torque ripples must be mitigated. Torque ripples consist of two main components which are cogging torque and ripple torque. The cogging torque is produced by the interaction between the reluctance variation in stator and rotor magnetic flux. The ripple torque is mainly generated by the interaction of the stator current magnetomotive force and rotor magnetic flux distribution in the surface PM (SPM) machines [3]. Both the cogging and ripple torque are related to rotor magnetic flux distribution which is manipulated by the shape of PM in the SPM machines.
In the literature, various topologies were investigated in order to reduce torque ripple. The shaping of rotor magnet pole was realized by the skewing or displacing of magnet poles [4]. The stator slot shaping was proposed $[5,6]$. Many other torque ripple reducing approaches are summarized in $[1,7]$. Some researches focused on the predicting of torque ripple effects [8]. Beyond the prediction and minimization, the manufacturing process is taken into account in [9, 10]. This paper suggests the two step on rotor magnet poles with a shift angle implementation.

\section{PROPOSED DESIGNS}

The single air gap axial flux machine is taken into account as the reference design (see Figure 1 and Table I for the studied motor reference parameters). Design I, is a conventional axial flux permanent magnet machine model and the reference model for the study (Figure 2(a)). This type of magnet can be found in the market easily. Design II, is the proposed model and it can be seen in Figure 2(b). This design is the novel proposal for the axial flux machines. It is studied in order to determine its effect in reducing the torque ripples. The motor rotation was $2200 \mathrm{rpm}$. Both transient and static analyses are performed. Runtime process is done for $10 \mathrm{~ms}$ so motor turns more than one time during the simulation. The most used performance characteristics obtained from the analysis are moving torque and back EMF waveforms. While moving torque values were taken with the current supply, back EMF waveform were taken with zero current. M250-35A steel specifications were used for the defining of the steel parameters of the stator and the rotor. The cylindrical coordinate system is used to define the axial flux steel orientation.

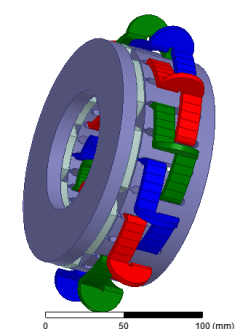

Fig. 1. The studied AFPM motor topology 
All the permanent magnet poles are magnetized in $\mathrm{z}$-axis and the all of the PM volumes, inner and outer diameters are the same for each pole design. Magnet fill factor is 0.87 in each design.

TABLE I. REFERENCE PARAMETERS

\begin{tabular}{|c|c|}
\hline Parameter & Value \\
\hline Inner radius $\left(\mathrm{r}_{\mathrm{i}}\right)$ & $40 \mathrm{~mm}$ \\
\hline Outer radius $\left(\mathrm{r}_{\mathrm{o}}\right)$ & $75 \mathrm{~mm}$ \\
\hline Stator thickness & $50 \mathrm{~mm}$ \\
\hline Slot number & 24 \\
\hline Pole number & 8 \\
\hline Maximum current & $175 \mathrm{~A}$ \\
\hline Current waveform & Sinusoidal \\
\hline Moving speed & $2200 \mathrm{rpm}$ \\
\hline Magnet fill factor & 0.87 \\
\hline Magnet height & $5 \mathrm{~mm}$ \\
\hline Slot opening width & $2 \mathrm{~mm}$ \\
\hline Air gap & $1 \mathrm{~mm}$ \\
\hline
\end{tabular}

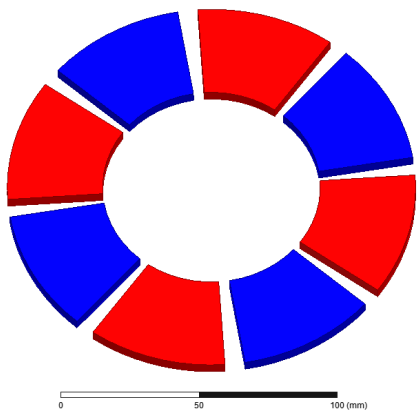

(a) Design I

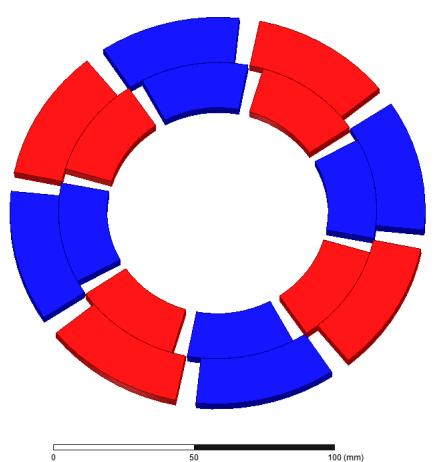

(b) Design II

Fig. 2. Magnet designs (a) Solid magnet poles b) Two-step magnet poles with shift angle

\section{SHIFTING ANGLE}

The shifting angle means that inner rotor step magnets are displaced by an angle from the outer rotor magnets as seen in Figure 2(b). One of the aims of this shifting method is the mitigation of the torque ripples. There are several analytical methods to define the best shift angle. One of them is the cogging torque period method described in [11]. But this method doesn't give the best correct result for the axial flux permanent magnet machines. In this research, parametric analysis with 3-D FEA is used to find the optimum shifting angle. The shifting angle defined as a variable and differs from $0^{\circ}$ to $14^{\circ}$ by $1^{\circ}$ step. The moving torque values were taken into account for each result. Figure 3 demonstrates the results of the parametric analysis. Table II shows each torque ripple and average torque value for each shifting angle. The simulation's parametric analysis gave interesting results. If the torque ripple is the most important anchor of the application, the best result is the $11^{\circ}$ shifting angle which produces $2.16 \mathrm{Nm}$ of peak to peak cogging torque. But if the average torque value is the most valued parameter, $3^{\circ}$ shifting angle produce the highest average torque of $51.27 \mathrm{Nm}$ which is $1.3 \mathrm{Nm}$ higher than that of the $0^{\circ}$ shifting angle. Torque ripple drops from the shifting angle $1^{\circ}$ to $11^{\circ}$, but after $11^{\circ}$ it starts to rise again.

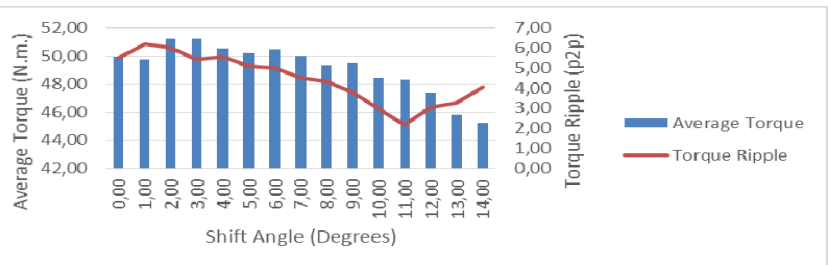

Fig. 3. Defining the shifting angle by parametric analysis.

TABLE II. PARAMETRIC ANALYSIS RESULTS

\begin{tabular}{|c|c|c|}
\hline Shift Angle & Average Torque & Torque Ripple \\
\hline 0 & 49.95 & 5.52 \\
\hline 1 & 49.77 & 6.23 \\
\hline 2 & 51.24 & 6.04 \\
\hline 3 & 51.27 & 5.44 \\
\hline 4 & 50.58 & 5.59 \\
\hline 5 & 50.21 & 5.11 \\
\hline 6 & 50.46 & 5.02 \\
\hline 7 & 50.00 & 4.51 \\
\hline 8 & 49.35 & 4.34 \\
\hline 9 & 49.47 & 3.77 \\
\hline 10 & 48.46 & 2.98 \\
\hline 11 & 48.32 & 2.16 \\
\hline 12 & 47.37 & 3.06 \\
\hline 13 & 45.81 & 3.25 \\
\hline 14 & 45.25 & 4.04 \\
\hline
\end{tabular}

IV. RESUlts

Static and dynamic simulations were run for each design. The stator was split out to four identical parts and, due to the symmetrical geometry and for reducing simulation time and one of them was studied (because of the 3D geometry, just one of the simulations takes nearly three hours). In the static analysis, the stator and the windings are stated fix. Just rotor magnet poles and the rotor back iron are moving $90^{\circ}$ with $15^{\circ}$ steps. The simulation results can be seen at Table III which demonstrates the average values of the waveforms taken from each step. The magnetic force equals to the total magnetic force on the rotor side. It consists of three dimensional forces. The highest magnetic force value is taken from the simulation of the second design and the lowest data is taken from the first design. In dynamic analysis, PMs having $11^{\circ}$ shifting angle are used in Design II. Moving torque and back EMF waveforms are taken from the dynamic simulations. Figure 4 shows the moving torque results of the two designs shown in Figure 2. The 
comparison of the two designs is demonstrated in Table IV. We see that in Design II torque ripple and average torque reduced by $62,4 \%$ and $4,3 \%$ respectively. Voltages induced in the windings are given by (1) obtained from Faraday's law. The left side of the equation is called transformer voltage and the right one is called back EMF and is induced in the stator windings because of the magnet flux passing through the air gap. As seen in (1) back EMF is directly proportional to the mechanical speed and the simultaneous changes of the inductance. The magnet shifting and stepping also influences the inductance.

TABLE III. AVERAGE VALUES OF MAGNETIC FORCE FOR EACH ROTOR MAGNET POLE DESIGN

\begin{tabular}{|c|c|c|}
\hline & Design I & Design II \\
\hline Magnetic Force (N) & 743.47 & 1203 \\
\hline
\end{tabular}

$$
e_{\text {ind }}=L \frac{d I}{d t}+w I \frac{d L}{d \theta}
$$

Figure 5 illustrates the back electromotive force waveforms of each design. The smoothness of these waveforms is crucial in order to have more constant torque which means having lower torque ripple. Design two has smoother back EMF and lower torque ripple waveforms. Flux density distributions are posed in Figure 6 for the two designs which demonstrate the radial components of the flux density between the magnets and the stator steel.

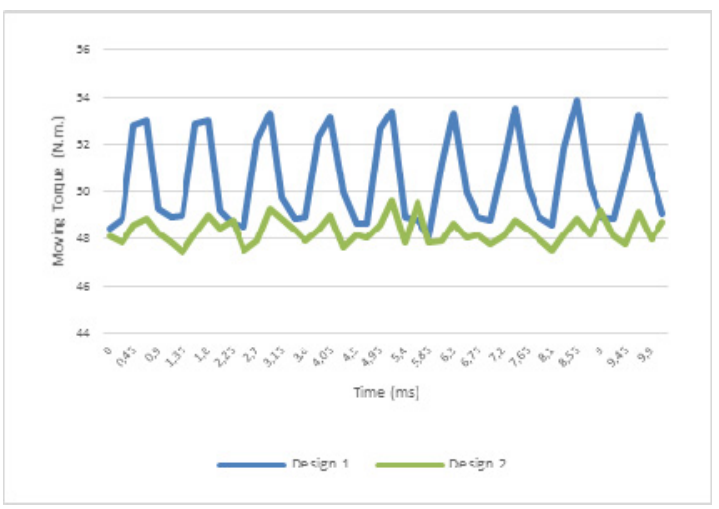

Fig. 4. Torque ripple mitigation results

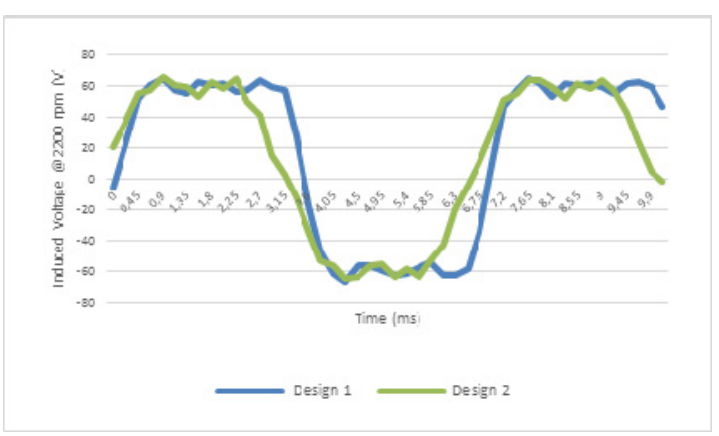

Fig. 5. Back EMF results
TABLE IV. COMPARISON OF SIMULATION RESULTS CONCERNING AVERAGE TORQUE AND TORQUE RIPPLE

\begin{tabular}{|c|c|c|}
\hline & Design I & Design II \\
\hline Average Torque (AT) & 50.521 & 48.32 \\
\hline Torque Ripple (TR) & 5.744 & 2.159 \\
\hline Rate (TR/AT) & 0.114 & 0.045 \\
\hline AT Reduction & ref. & $-\% 4.3$ \\
\hline TR Reduction & ref. & $-\% 62.4$ \\
\hline
\end{tabular}

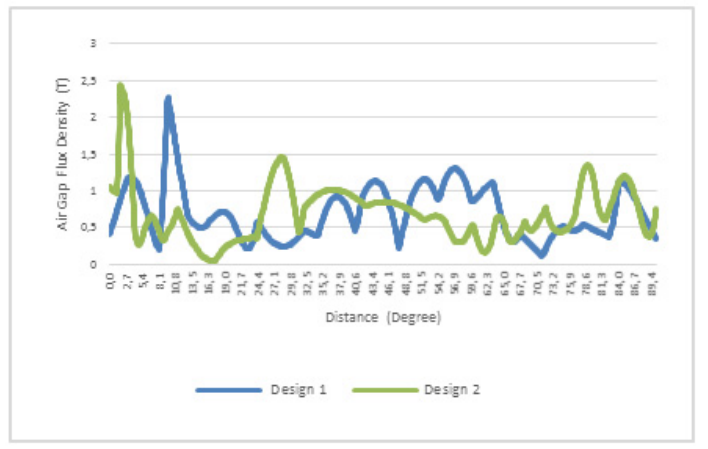

Fig. 6. Magnetic flux densities of the designs

\section{CONCLUSION}

This study deals with the stepping and shifting effects of a novel design of the rotor magnets for the AFPM machines considering torque ripple reduction. TR/AT values prove that the proposed design has lower average torque and torque ripple than the reference design. The reference design (Design I) is simulated in order to prove the stepping and shifting effects on performance characteristics. Dynamic and static analysis are performed in this study and each design's performance is discussed in the simulation results. Also, a parametric analysis is fulfilled to determine the shifting angle correctly. The average magnetic force results are obtained from the static analysis. The highest magnetic force is created in the second design. The moving torque and the back EMF waveforms are obtained from the dynamic analysis. Magnetic flux density distribution waveforms show that the second design performs better in torque ripple mitigation due to the precision on constancy of moving torque.

\section{ACKNOWLEDGEMENT}

This study is supported by the TUBITAK (The Scientific and Technical Research Council of Turkey).

\section{REFERENCES}

[1] F. Giulii Capponi, G. De Donato, F. Caricchi, "Recent advances in axial-flux permanent-magnet machine technology", IEEE Transactions on Industry Applications, Vol. 48, No. 6, pp. 2190-2205, 2012

[2] J. F. Gieras, R. J. Wang, M. J. Kamper, Axial Flux Permanent Magnet Brushless Machines, Springer Science \& Business Media, pp.3-19, 2005

[3] T. M. Jahns, W. L. Soong, "Pulsating torque minimization techniques for permanent magnet ac drives - A review", IEEE Transactions on Industrial Electronics, Vol. 43, pp. 321-330, 1996

[4] M. Aydin, Z. Q. Zhu, T. A. Lipo, D. Howe, "Minimization of Cogging Torque in Axial-Flux Permanent-Magnet Machines: Design Concepts", IEEE Transactions on Magnetics, Vol. 43, No. 9, pp. 3614-3622, 2007 
[5] S. J. Sung, S. J. Park, G. H. Jang, "Cogging torque of brushless DC motors due to the interaction between the uneven magnetization of a permanent magnet and teeth curvature", IEEE Transactions on Magnetics, Vol. 47, No. 7, pp. 1923 -1928, 2011

[6] D. G. Dorrell, M. Popescu, "Odd stator slot numbers in brushless dc machines-An aid to cogging torque reduction", IEEE Transactions on Magnetics, Vol. 47, No. 10, pp. 3012-3015, 2011

[7] M. Aydin, T. A. Lipo, "Axial Flux Permanent Magnet Disc Machines: A Review”, SPEEDAM, pp. 61-71, 2004

[8] Z. Q. Zhu, D. Howe, "Analytical prediction of the cogging torque in radial-field permanent magnet brushless motors", IEEE Transactions on Magnetics, Vol. 28, No. 2, pp. 1371-1374, 1992
[9] L. Gasparin, A. Cernigoj, S. Markic, R. Fiser "Additional cogging torque components in permanent-magnet motors due to manufacturing imperfections", IEEE Transactions on Magnetics, Vol. 45, No. 3, pp. $1210-1213,2009$

[10] M. A. Khan, I. Husain, M. R. Islam, J. T. Klass , "Design of experiments to address manufacturing tolerances and process variations influencing cogging torque and back EMF in the mass production of the permanentmagnet synchronous motors", IEEE Transactions on Industry Applications, Vol. 50, No. 1, pp. 346-355, 2014

[11] C. Y. Hsiao, S. N. Yeh, J. C. Hwang, "A Novel Cogging Torque Simulation Method for Permanent-Magnet Synchronous Machines", Energies, Vol. 4, No. 12,pp. 2166-2179, 2011 